\title{
ANÁLISE QUALI-QUANTITATIVA DA ARBORIZAÇÃO DO MUNICÍPIO DE GUATAMBU,SC
}

\author{
Tanny Bohner ${ }^{1}$, Cibele Rosa Gracioli², Cristina Gouvêa Redin ${ }^{3}$, Daniela Thomas da Silva ${ }^{3}$, \\ Solon Jonas Longhi ${ }^{4}$, Marcelo Barcellos da Rosa ${ }^{5}$ \\ ${ }^{1}$ Engenheira Florestal, Pós-graduanda do Curso de Especialização em \\ Educação Ambiental da UFSM, RS. \\ tanny.bohner@hotmail.com \\ ${ }^{2}$ Eng. Florestal, Profa. Dra. Universidade Federal do Pampa - Campus São Gabriel, RS. \\ cibelegracioli@gmail.com \\ ${ }^{3}$ Engenheira florestal, Aluna de pós-graduação em Engenharia Florestal, CCR/UFSM, RS. \\ crys luanova@hotmail.com \\ ${ }^{3}$ Engenheira florestal, Aluna de pós-graduação em Engenharia Florestal, CCR/UFSM, RS. \\ danyzinha th@hotmail.com \\ ${ }^{4}$ Professor titular do Departamento de Engenharia Florestal, UFSM. \\ solon.longhi@ufsm.br \\ ${ }^{5}$ Professor do Curso de Especialização em Educação Ambiental da UFSM. \\ marcelobdarosa@gmail.com
}

\section{RESUMO}

O objetivo deste trabalho foi avaliar a densidade de árvores, riqueza de espécies e possíveis conflitos na arborização do município de Guatambu, SC, sugerindo medidas alternativas para solucionar os problemas existentes. Neste sentido, foram levantados alguns dados como: o nome da espécie arbórea; altura $(\mathrm{m})$, Circunferência a Altura do Peito $(\mathrm{cm})$; distância entre as árvores (m); sanidade; e presença ou ausência de área livre adequada. Os dados foram coletados em formulários específicos e transferidos para planilha específica. Registrou-se a existência de 80 exemplares, distribuídos em 9 espécies, 9 gêneros e 7 famílias botânicas. As espécies mais abundantes foram Ligustrum lucidum e Balforodendrum riedelianum. Os maiores conflitos observados foram a pequena dimensão de área livre e árvores muito jovens para o plantio. Ainda, a implantação de espécies exóticas em restrição às nativas diminui o nível de diversidade da paisagem.

Palavras chave: Arborização, conflitos, porte arbóreo, espécies nativas.

\begin{abstract}
This work aimed to evaluate the density of trees, wealth of species and possible afforestation conflicts in the city of Guatambu, suggesting alternative measures to solve the existing problems. In this sense, some data were lifted Up, such as: the arboreal species; height $(\mathrm{m}), \mathrm{BHC}(\mathrm{cm})$; distance among the trees; sanity; and presence or absence of appropriate free area $\left(1 \mathrm{~m}^{2}\right)$. The data were collected on specific forms and transferred to specific spreadsheet. It was registered the existence of 80 individuals, distributed in 9 species, 9 genders and 7 botanical families. The most abundant species were Ligustrum lucidum e Balforodendrum riedelianum. The biggest conflicts observed were the unsuitable tree sizes concerning the small free area dimension and the use of young trees. Thus, the use of exotic species in restriction to native ones decreases the diversity rate of the landscape.
\end{abstract}

Keywords: Afforestation, conflicts, arboreal size, native species. 


\section{Monografias Ambientais}

REMOA (Revista Eletrônica do Curso de Especialização em Educação Ambiental da UFSM)

\section{INTRODUÇÃO}

A arborização das cidades constitui-se em um elemento de grande importância para a elevação da qualidade de vida da população, seja em grandes centros urbanos quanto em pequenas cidades. Além da função paisagística, proporciona outros benefícios à população, controlar muitos efeitos adversos do ambiente urbano melhorando o ambiente urbano tanto no aspecto ecológico quanto na sua estética. Com suas características, são capazes de controlar muitos efeitos adversos do ambiente urbano, contribuindo para uma significativa melhoria na qualidade de vida, tais como: purificação do ar pela fixação de poeiras e gases tóxicos e pela reciclagem de gases através dos mecanismos fotossintéticos (ruas bem arborizadas podem reter até $70 \%$ da poeira em suspensão); equilíbrio ambiental; melhoria do microclima da cidade, pela retenção de umidade do solo e do ar e pela geração de sombra, evitando que os raios solares incidam diretamente sobre as pessoas; redução na velocidade do vento, influência no balanço hídrico, favorecendo a infiltração da água no solo e provocando evapotranspiração mais lenta; abrigo à fauna, propiciando uma variedade maior de espécies, e o que influencia positivamente ao ambiente, pois propicia maior equilíbrio das cadeias alimentares e diminuição de pragas e agentes vetores de doenças e amortecimento de ruídos (EMBRAPA, 2000; SANTOS e TEIXEIRA, 2001;).

Os requisitos básicos são planejar harmoniosamente e concomitantemente a arborização e as intervenções urbanas, programar o atendimento permanente das necessidades da arborização e assegurar condições essenciais à concretização dos programas de arborização (MESQUITA,1996).

O maior problema da arborização urbana está no conflito que se estabelece entre as árvores e os demais elementos que compõem o ambiente. A solução para tal conflito se encontra na escolha adequada das espécies arbóreas, tendo-se em vista diversas finalidades a serem cumpridas no ecossistema urbano (GONÇAVES e PAIVA, 2004).

Segundo Paiva (2000), para implantar a arborização é importante escolher as espécies e avaliar alguns critérios, como o ritmo e as exigências para o crescimento, o tipo de copa, o porte, a folhagem, as flores, os frutos, os troncos, as raízes, os problemas de toxidez, a rusticidade, a resistência, a desrama natural e a origem das espécies; além de considerar outros fatores relevantes, entre eles, a largura da calçada, a rede de infra-estrutura, o clima, o solo e a umidade.

A escolha da espécie adequada para ser utilizada em um determinado local é fundamental quando se planeja a arborização urbana. Uma escolha bem feita diminui os custos de manutenção que ocorrem quando colocadas em local errado. Existem critérios a ser adotados: em canteiros centrais de avenidas e em ruas de calçadas largas, pode-se optar por espécies de porte grande e médio, porém em calçadas estreitas, devem-se usar espécies de pequeno porte para não causar interferências principalmente com a rede de infraestrutura. Para a seleção de árvores de rua é necessário considerar: desenvolvimento, porte, características da copa, floração, frutificação, resistência a pragas, doenças e poluição, ausência de princípios tóxicos e de preferência que sejam nativas. Ainda, as árvores precisam ter boa estrutura, ser fortes, não devem ter galhos quebradiços e raízes superficiais, devem ser tolerantes as características do solo urbano, precisar de pouca manutenção e, acima de tudo, serem bonitas o ano todo (PHILLIPS, 1993).

Segundo Pivetta e Silva Filho (2002) para que uma árvore possa ser utilizada na arborização urbana sem trazer inconvenientes, deve apresentar resistência a pragas e doenças, crescimento médio a rápido, não produzir frutos grandes, ter lenho resistente, ser livres de espinhos, não conter princípios tóxicos ou alergênicos, flores de tamanho pequeno, sem odores fortes, ser nativa ou, se exótica, deve ser adaptada, ter folhagem de renovação e tamanho favoráveis, copa com forma e tamanho adequados, sistema radicular profundo e bom efeito estético. 


\section{Monografias Ambientais}

REMOA (Revista Eletrônica do Curso de Especialização em Educação Ambiental da UFSM)

Planejar a arborização é indispensável para o desenvolvimento urbano, para não acarretar prejuízos ao meio ambiente. A arborização tem influência direta sobre o bem-estar do homem em razão dos múltiplos benefícios que proporciona ao meio. Assim, é um fator fundamental na salubridade ambiental (DANTAS e SOUZA, 2003).

Nas cidades onde já está implantada a arborização urbana, é necessário

acompanhamento técnico, bem como reformulação do planejado, observando os seguintes condicionantes: estudo da espécie, comportamento no meio urbano, integralização com os outros elementos da cidade, dimensões de ruas e passeios, altura das construções, presença de redes aéreas ou subterrâneas, localização das diferentes atividades, condições de clima e solo, fluxo de veículos e pedestres (CUNHA et al., 2005).

O processo de avaliação da arborização, tanto qualitativo como quantitativo depende, assim, da realização de inventários que, em função de objetivos especialmente definidos, são fundamentados em diferentes metodologias e podem apresentar diferentes graus de precisão. A realização do inventário quantitativo da arborização pública permite definir e mapear com precisão a população total de árvores de ruas para fins de inventário qualitativo, além da identificação da composição real da arborização entre outros aspectos. O inventário é o passo inicial para o replanejamento da arborização por meio de um Plano Diretor (MILANO, 1983; TEIXEIRA, 1999; PIVETTA e FILHO, 2002).

Para que a presença da árvore na via pública não seja inconveniente e não venham a causar problemas no futuro, há necessidade da escolha das espécies que apresentem características favoráveis à arborização. É importante considerar a origem da espécie, dando preferência àquelas nativas da região, adaptadas ao local, contribuindo assim para sua conservação. As espécies exóticas somente devem ser introduzidas quando aclimatadas às condições locais. Portanto, deve haver um planejamento adequado considerando aspectos culturais e históricos da população local, com suas necessidades e aspirações, bem como o espaço físico disponível. (PEDROSA 1983; ELETROPAULO, 1995; PRASS, 2004).

No planejamento da arborização, deve-se levantar a caracterização física de cada rua, para definição dos critérios que condicionam a escolha das espécies mais adequadas a cada região. Três tipos de critérios devem ser considerados no planejamento da arborização urbana. O primeiro leva em conta o aspecto visual-espacial, definindo o tipo de árvore que melhor se adapta ao local em termos paisagísticos. O segundo considera as limitações físicas e biológicas que o local impõe ao crescimento das árvores. O terceiro, funcional, avalia quais as espécies mais adequadas para melhorar o microclima e outras condições ambientais (AMIR e MISGAV, 1990).

É importante que a diversidade de espécies seja respeitada e que se dê preferência às árvores comuns da região. Deve-se evitar a arborização de um bairro ou cidade com uma única espécie. Ao recomendar-se a diversificação das espécies, isto não implica que se deva plantá-las aleatoriamente. As árvores devem ser distribuídas nas ruas de uma forma estética e paisagística. (LIMA, 1995).

Segundo Soares (1998), a arborização de passeios requer cuidados especiais. Não podem ser utilizadas árvores frondosas, pois por mais afastadas que elas estejam das casas elas sempre impedem a insolação das fachadas. As poeiras acumuladas nas folhagens e as próprias folhas podem ser jogadas pelos ventos para as calhas dos beirais e até para o interior das casas. 0 sombreamento excessivo dos prédios prejudica a distribuição da luz difusa, insistentemente reclamada pela higiene, em virtude da sua ação bactericida. 


\section{Monografias Ambientais}

REMOA (Revista Eletrônica do Curso de Especialização em Educação Ambiental da UFSM)

Em canteiros centrais, presentes em avenidas, pode se utilizar árvores de médio a grande porte, caso este possua grandes dimensões (mais de 4 metros de largura), ou então espécies colunares, como as palmeiras. Elas apresentam forma adequada para este fim, além de servirem como referência aos condutores de automóveis. Porém não são apropriadas para uso em calçadas, seja pelo porte, na maioria das vezes grande como também pela dificuldade de manejo. Sempre que possível, deve-se utilizar espécies nativas, mas se estas não estiverem disponíveis, pode se utilizar espécies exóticas adaptadas (MARTO et al., 2006).

Portanto, a arborização necessita, como qualquer outra atividade, de profissionais bem capacitados para a sua realização. Pessoas leigas tendem a prezar, muitas vezes, apenas pelo aspecto beleza. Mesmo que apresente relevante importância, outros aspectos devem ser respeitados, afim de que a arborização proporcione bem estar, não trazendo transtornos (GRAZIANO, 1994).

Levando-se em consideração a importância de um correto planejamento da arborização urbana, esse trabalho tem o objetivo de caracterizar os padrões qualitativos e quantitativos das espécies arbóreas presentes nas principais ruas do município de Guatambu - SC, avaliando fatores como a riqueza de espécies, porte dos indivíduos, bem como estado fitossanitário, ocorrência de área livre ou não e ocorrência de podas.

\section{REVISÃO BIBLIOGRÁFICA}

A importância da arborização urbana

A vegetação urbana é representada por conjuntos arbóreos de diferentes origens e que desempenham diferentes papéis nas mais diferentes localidades, desempenha diversas funções ligadas e influenciadas por aspectos sociais, culturais, econômicos, e, sobretudo ecológicos, interferindo fortemente nas condições de conforto ambiental (FILHO, 1985).

As praças e as ruas constituem os mais importantes espaços públicos na história das cidades do Brasil. Esses espaços são, na maioria das vezes, configurados pela massa construída e pelo suporte físico em suas várias formas de modelagens e condicionados pela formas de propriedades e parcelamentos decorrentes. Assim, somente os parques, alguns jardins e praças são configurados pela vegetação. Nas cidades, há os chamados espaços livres de edificação, como as ruas (MACEDO, 1999; ROBBA e MACEDO, 2003).

Os jardins urbanos são espaços livres fundamentais para a melhoria da qualidade ambiental, pois permitem melhor circulação do ar, insolação e drenagem, além de servirem como referenciais cênicos da cidade. (ROBBA e MACEDO, 2003).

A vegetação viária é, ainda, muito importante para a integração dos parques e das áreas verdes urbanas, funciona como corredor para fauna, reduzindo o problema de isolamento, colaborando assim com a natureza (CAVALHEIRO, 1991).

As paisagens estão em constante transformação, tanto no contexto ecológico quanto no contexto cultural. Ao planejar paisagens, devem ser considerados o contexto temporal e espacial, a história, as fases ecológicas e os períodos culturais, justamente para se adequar ao dinamismo dessa mudança de paisagens (MARCUCCI,2000).

O projeto de arquitetura paisagística sempre está aplicado a um objeto, seja ele uma rua, um jardim ou um parque. (MACEDO, 1999) 


\section{Monografias Ambientais}

REMOA (Revista Eletrônica do Curso de Especialização em Educação Ambiental da UFSM)

Segundo Goya (1994), as árvores são referências marcantes que se possui de uma cidade e substituí-las é despir o local de parte de sua memória, mudando significantemente sua imagem. Este mesmo autor lembrou que as árvores de cada cidade são parte integrante da memória urbana, sem a qual não se pode vislumbrar o futuro.

Independente da beleza intrínseca reconhecida na vegetação que faz parte das áreas verdes, o tratamento paisagístico pode melhorar a composição estética da paisagem urbana, cumprindo sua missão de plano estético acoplando a relação homem-natureza (FAMURS, 2000).

$O$ projeto de arquitetura paisagística é o resultado direto de uma ação programada. A concepção da paisagem urbana é um trabalho de paisagismo e exige o cuidado de paisagistas, para que apresentem alta qualidade. O projeto do espaço público nunca está dissociado do contexto urbano no qual está inserido, mesmo que esteja inserido dobre um fragmento ou um grande loteamento (MACEDO, 1999).

De acordo com Furtado \& Melo Filho (1999), todos os elementos paisagísticos devem ser cuidadosamente tratados a fim de trazer benefícios que interferirão no projeto integrado, visando a melhoria da qualidade do ar, o sombreamento da edificação e adjacências, o controle da ventilação e da umidade. A maior parte da carga térmica de uma edificação provém da radiação solar e da temperatura do ar exterior, sendo necessário um rigoroso controle dos elementos microclimáticos para eliminar um excesso de energia que tornaria inóspito o ambiente construído.

Problemas decorrentes da falta de planejamento

A arborização urbana resguarda sempre um pouco da flora original das cidades. Porém, quando mal planejada e realizada por pessoal inapto, pode ter influência negativa direta em alguns elementos da organização urbana como redes de distribuição de energia elétrica e telefônica e sistemas de abastecimento de água e esgoto (DEMATTÊ,1997; MENESES et al., 2003).

A arborização urbana e os outros elementos existentes na maioria dos centros urbanos, como postes de iluminação pública, fiações, telefones públicos, placas de sinalização convivem em desarmonia devido à ausência de planejamento tanto da arborização, quanto dos outros elementos. Nenhum ambiente é mais alterado que o meio urbano, devido aos atuais modelos de edificações e loteamento do solo que restringem os espaços determinados às áreas verdes. Essas restrições limitam a utilização de árvores na Floresta Urbana, em relação ao seu porte e à quantidade de espécies (YAMAMOTO et al., 2004).

Milano (1987) considera as condições ambientais, o espaço físico disponível e as características das espécies os três fatores condicionantes para o planejamento da arborização.

Seguindo Gonçalves e Paiva (2004), a presença de fiação nas ruas é considerada uma das mais importantes definidoras do planejamento da arborização urbana.

A arborização implantada de forma mal planejada ou mal conduzida pode proporcionar, além dos danos à rede elétrica, a perda da eficiência da iluminação pública, o entupimento de calhas e bueiros, danos aos muros e telhados, além de dificultar a passagem de veículos ou pedestres, o que fiz com que a atividade de poda constitua-se em exercício indispensável a manutenção de razão padrões urbanísticos (CESP, 1995).

A inadequação das espécies utilizada na arborização de logradouros públicos tem trazido como conseqüência custos crescentes na manutenção e reparos da rede aérea de fios e cabos, assim como a infra-estrutura subterrânea, composta por dutos e galerias. Para reduzir a 


\section{Monografias Ambientais}

REMOA

(Revista Eletrônica do Curso de Especialização em Educação Ambiental da UFSM)

ocorrência desses danos, devem ser selecionadas árvores com portes diferenciados, compatíveis com fiações e interferências subterrâneas. Sendo eliminadas aquelas que se caracterizam por apresentarem a madeira mole, caule e ramos quebradiços, pois são vulneráveis a chuvas e ventos fortes, colocando em risco a segurança de pedestres, veículos e edificações. As árvores com raízes superficiais também devem ter o plantio limitado a locais onde suas raízes não danifiquem o pavimento (FRANCO, 1993).

\section{MATERIAIS E MÉTODOS}

Descrição da área de estudo

O estudo foi desenvolvido na cidade de Guatambu, situado na região oeste do estado de Santa Catarina, na microrregião de Chapecó, a $594 \mathrm{~km}$ de Florianópolis. Apresenta uma área de $206 \mathrm{~km}^{2}$ e possui 4.702 habitantes. Situada $530 \mathrm{~m}$ acima do nível do mar, possui clima é Mesotérmico úmido, com verão quente e temperatura média de $17,6^{\circ} \mathrm{C}$. Os municípios limites são Chapecó, Águas de Chapecó, Caxambu do Sul, Planalto Alegre e São Carlos (GOVERNO DO ESTADO DE SANTA CATARINA, 2010). De acordo com a Embrapa (1999), o solo desta região é classificado como Latossolo Vermelho distroférrico típico.

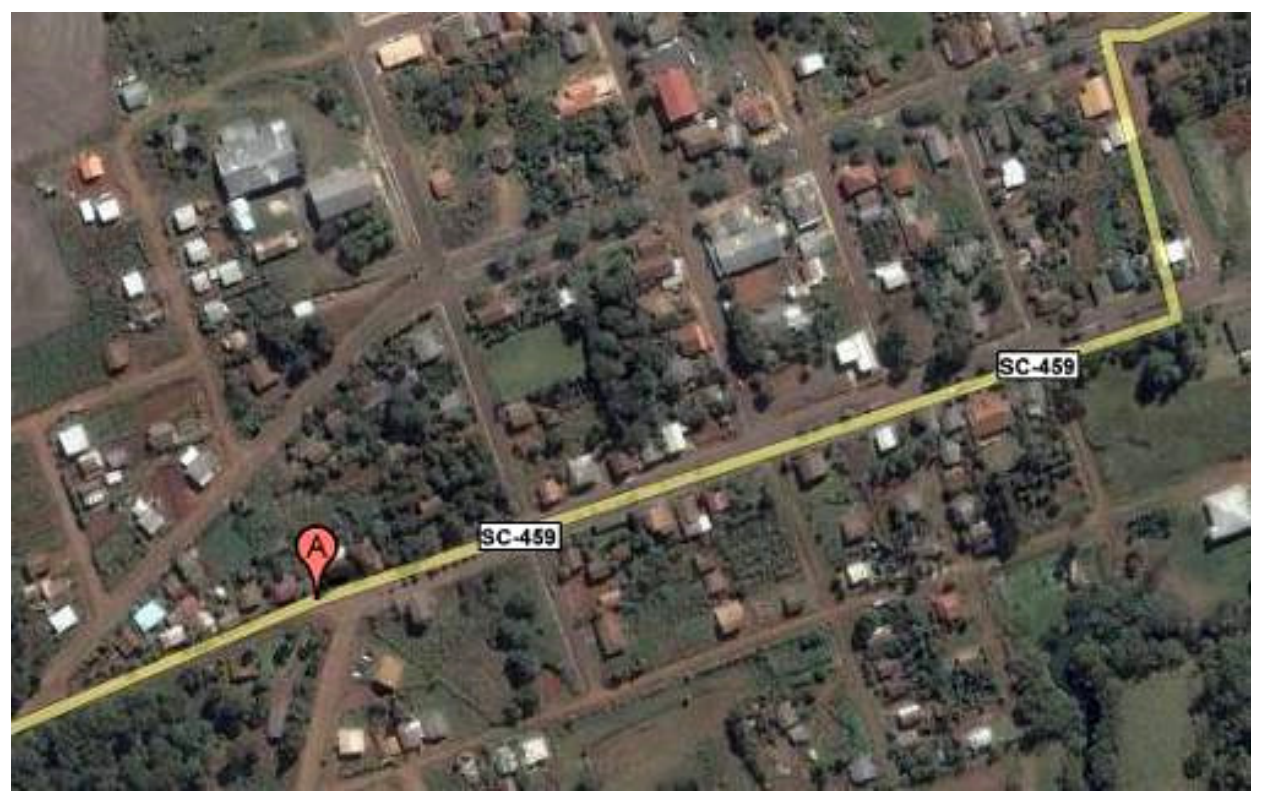

FIGURA 1 - Aspecto do Município de Guatambu, Santa Catarina, 2010. Fonte: Google Earth, (2010)

Breve histórico do município

Os primeiros colonizadores foram atraídos à região pela possibilidade de lucrar com a extração da madeira, especialmente a araucária. A grande quantidade da madeira-de-lei chamada guatambu deu nome ao local. Eram descendentes de italianos, alemães e alguns caboclos, 


\section{Monografias Ambientais}

REMOA (Revista Eletrônica do Curso de Especialização em Educação Ambiental da UFSM)

oriundos do Rio Grande do Sul. A mão-de-obra familiar era predominante, tradição que se mantém até hoje. Guatambu emancipou-se de Chapecó em 12 de dezembro de 1991. A principal atividade econômica é a agricultura o cultivo de milho, feijão e a criação de frangos e perus. Uma importante característica do município é a variedade de sua fauna preservada. (GOVERNO DO ESTADO DE SANTA CATARINA, 2010).

\section{Amostragem}

Foi realizado um censo da arborização da área central da cidade de Guatambu, SC. As ruas avaliadas foram Ângelo Corá, João Moreira Filho e Avenida João Batista. O estudo foi realizado no mês de abril de 2010.

A avaliação foi feita com base na determinação da espécie arbórea; com suas variáveis dendrométricas, classe de altura $(\mathrm{m})$ e Circunferência a altura do peito - CAP $(\mathrm{cm})$. Os demais fatores observados foram: ocorrência ou não de poda; estado fitossanitário (ataque de pragas ou organismos patogênicos e injúrias mecânicas); distância entre exemplares e; presença ou ausência de área livre adequada.

Os dados foram coletados em planilha específica (Anexo 1), e após transferidos para o software Microsoft Office Excel ${ }^{\circledR}$ 2003. As espécies mais comuns e freqüentes foram identificadas in loco, e as demais através de bibliografia adequada, bem como a determinação da origem das espécies (nativas ou exóticas). A classificação das famílias botânicas segue as orientações do Angiosperm Phylogeny Group (APG II).

As classes utilizadas neste trabalho foram:

a) Altura: Classe $1(<3 m)$; Classe $2(3,1-9 m)$; Classe $3(>9,1 m)$

b) Distância: Classe $1(<3 \mathrm{~m})$; Classe $2(3,1-6 \mathrm{~m})$; Classe $3(6,1-9 \mathrm{~m})$; Classe $4(9,1-12$ $\mathrm{m})$; Classe $5(12,1-15 \mathrm{~m})$; Classe $6(15,1-18 \mathrm{~m})$; Classe 7 (> 18,1 m)

c) CAP: Classe 1 (2 - $18 \mathrm{~m})$; Classe $2(18,1-34 \mathrm{~m})$; Classe $3(34,1-50 \mathrm{~m})$; Classe 4 (50,1 $66 \mathrm{~m})$; Classe $5(66,1-82 \mathrm{~m})$; Classe $6(82,1-98 \mathrm{~m})$; Classe 7 (> $98 \mathrm{~m})$

d) Sanidade: Classe 1 (Saudável); Classe 2 (Injúria mecânica); Classe 3 (Pragas); Classe 4 (Injúria mecânica e pragas);

\section{RESULTADOS}

O presente levantamento indicou a existência de 80 exemplares, distribuídos em 9 espécies, 9 gêneros e 7 famílias botânicas. A família de maior riqueza foi Fabaceae, enquanto as demais apresentaram somente uma espécie. As espécies mais abundantes foram Ligustrum lucidum e Balforodendrum riedelianum, reunindo $43,75 \%$ de todos os indivíduos. Em relação à origem, $76,25 \%$ dos indivíduos existentes são de origem exótica (Tabela 1). 


\section{Monografias Ambientais}

REMOA

(Revista Eletrônica do Curso de Especialização em Educação Ambiental da UFSM)

Tabela 1 - Espécies de árvores encontradas no município de Guatambu, com respectivas famílias botânicas, nome comum, porte, origem, abundâncias (N) e freqüências (Freq), Guatambu, SC, 2010.

\begin{tabular}{|c|c|c|c|c|c|}
\hline FAMÍLIA / ESPÉCIE & NOME VULGAR & PORTE & Origem & $\mathbf{N}$ & Freq \% \\
\hline \multicolumn{6}{|l|}{ Fabaceae } \\
\hline Caesalpinia peltophoroides & Sibipiruna & GP & $\mathrm{N}$ & 6 & 7,5 \\
\hline Leucaena leucocaephala & Leucena & GP & $\mathrm{E}$ & 2 & 2,5 \\
\hline $\begin{array}{l}\text { Tipuana tipu } \\
\text { Lauraceae }\end{array}$ & Tipuana & GP & $\mathrm{E}$ & 18 & 22,5 \\
\hline $\begin{array}{c}\text { Cinnamomum zeylanicum } \\
\text { Meliaceae }\end{array}$ & Canela-da-Índia & PP & $E$ & 10 & 12,5 \\
\hline $\begin{array}{c}\text { Melia azedarach } \\
\text { Moraceae }\end{array}$ & Cinamomo & GP & $E$ & 1 & 1,25 \\
\hline $\begin{array}{c}\text { Ficus benjamina } \\
\text { Oleaceae }\end{array}$ & figueira-benjamim & GP & $\mathrm{E}$ & 12 & 15 \\
\hline $\begin{array}{l}\text { Ligustrum lucidum } \\
\text { Rosaceae }\end{array}$ & Ligustro & GP & $E$ & 17 & 21,25 \\
\hline $\begin{array}{c}\text { Eryobotria japonica } \\
\text { Rutaceae }\end{array}$ & Nespereira & MP & $\mathrm{E}$ & 1 & 1,25 \\
\hline Balforodendrum riedelianum & Guatambu & GP & $\mathrm{N}$ & 13 & 16,25 \\
\hline SOMA & & & & 80 & $100 \%$ \\
\hline
\end{tabular}

Onde: PP = Pequeno porte; MP = Médio Porte; GP = Grande porte; Fontes: Lorenzi (2002), Lorenzi et.al. (2003), Tropicos (2008). N = Nativa; E= Exótica;

As espécies mais freqüentes na cidade de Guatambu foram Ligustrum lucidum $e$ Balforodendrum riedelianum.

Quanto ao porte das árvores, pode-se dizer que 37,5\% dos exemplares apresentam menos de 3 metros de altura e, quanto a circunferência a altura do peito (CAP), 38,75\% apresentaram o menor CAP (classe $2 \leq \mathrm{CAP} \leq 18$ ) como visto na tabela 2 . Assim, devido à maior parte dos indivíduos serem jovens e se enquadrarem na menor classe de alturas, como demonstrado na tabela 2, não apresentaram problema com a fiação.

Os maiores conflitos, tais como a pequena dimensão do canteiro para comportar uma árvore, também podem ser observados, já que a recomendação é de uma área superior a $1 \mathrm{~m}^{2}$, segundo Santos e Teixeira(2001) (figuras 2 e 3).

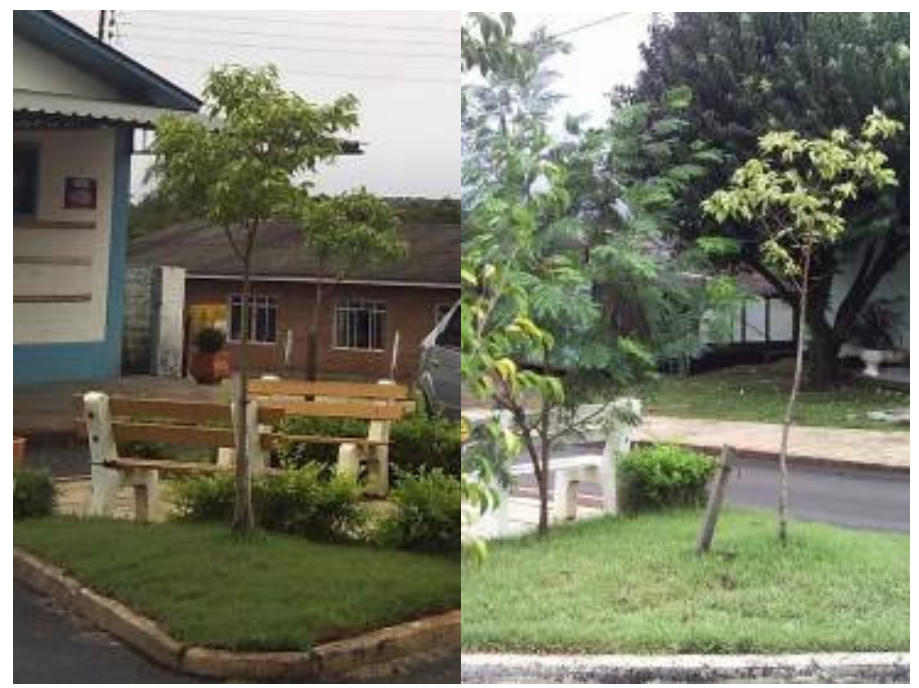

Figura 2 - Distância insuficiente a elementos arquitetônicos (banco). Rua (Fonte: Bohner, 2010.) 


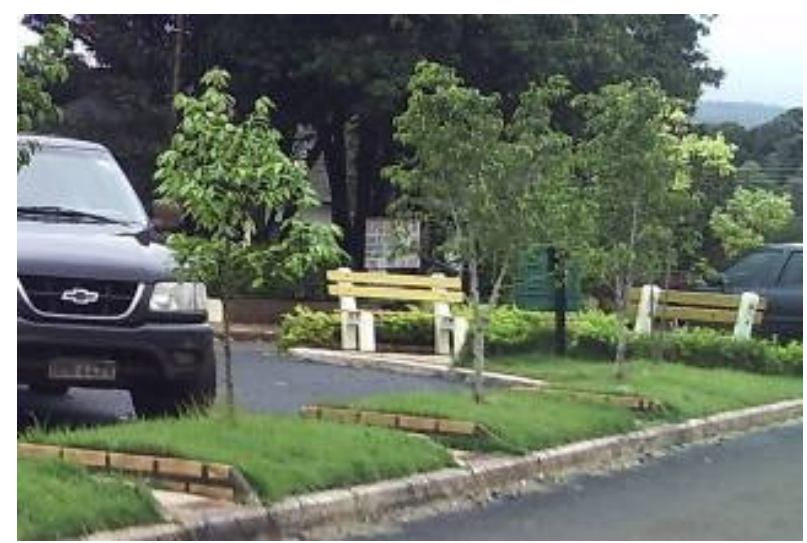

Figura 3 - Distância insuficiente entre indivíduos (Fonte: Bohner, 2010.).

Verificou-se também que algumas árvores eram muito jovens para o plantio, como pode ser visto na figura 3.

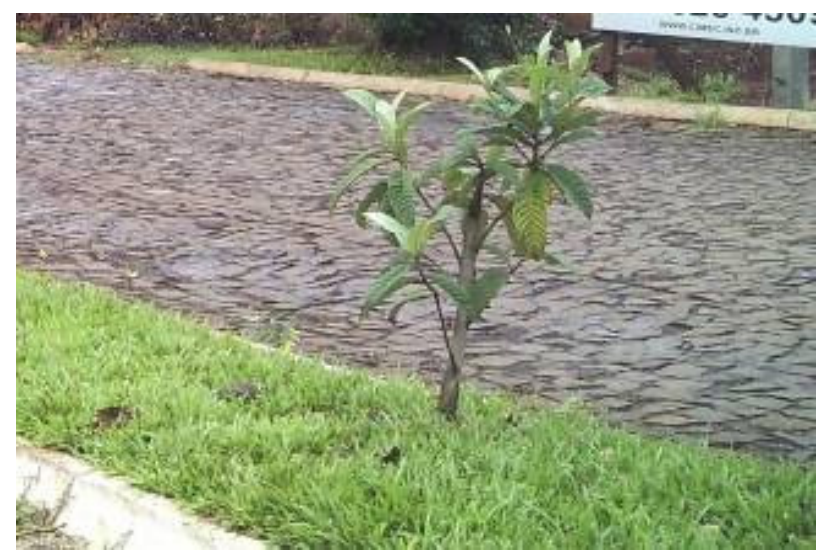

Figura 3 - Árvore muito jovem para o plantio (Fonte: Bohner, 2010.).

Quanto a altura e o porte, as espécies apresentaram uma freqüência de $37 \%$ de árvores de pequeno porte, ou seja, não apresentando conflito com fiação e elementos arquitetônicos. As demais espécies são de porte médio a grande, perfazendo $62 \%$ aproximadamente, denotando árvores com possível conflito nos locais onde estão implantadas, portanto, não sendo indicadas para calçadas laterais e sim, para canteiros centrais ou praças e parques, pois demandam amplo espaço físico (tabela 2). 


\section{Monografias Ambientais}

REMOA (Revista Eletrônica do Curso de Especialização em Educação Ambiental da UFSM)

Tabela 2 - Classes de altura $(\mathrm{m})$ e CAP $(\mathrm{cm})$ das árvores encontradas no município de Guatambu, com respectivas abundâncias (N) e freqüências (Freq), Guatambu, SC, 2010.

\begin{tabular}{|c|c|c|c|c|c|c|c|}
\hline Classe & $\begin{array}{c}\text { Altura } \\
\mathrm{h}(\mathrm{m})\end{array}$ & $\mathbf{N}$ & Freq \% & Classe & CAP $(\mathrm{cm})$ & $\mathbf{N}$ & Freq $\%$ \\
\hline 1 & $<3$ & 30 & 37,5 & 1 & $2-18$ & 31 & 38,75 \\
\hline 2 & $3,1 \leq h \leq 9$ & 27 & 33,75 & 2 & 18,1 - 34 & 20 & 25 \\
\hline \multirow[t]{6}{*}{3} & $>9,1$ & 23 & 28,75 & 3 & $34,1-50$ & 10 & 12,5 \\
\hline & & & & 4 & $50,1-66$ & 1 & 1,25 \\
\hline & & & & 5 & $66,1-82$ & 7 & 8,75 \\
\hline & & & & 6 & $82,1-98$ & 5 & 6,25 \\
\hline & & & & 7 & $>98$ & 6 & 7,5 \\
\hline & & 80 & 100 & & & 80 & 100 \\
\hline
\end{tabular}

Onde: $\mathrm{N}=$ número de indivíduos; Freq.\%= Frequência percentual de indivíduos

Em relação a presença ou ausência de área livre, verifica-se que $40 \%$ dos indivíduos apresentam área livre insuficiente, ou seja, menor que $1 \mathrm{~m}^{2}$, sendo não recomendável segundo Santos e Teixeira(2001) (tabela 3). E quanto à distância entre as árvores plantadas, verifica-se que $37,5 \%$

Tabela 3 - Área livre suficiente e distância entre as árvores encontradas município de Guatambu, com respectivas abundâncias (N) e freqüências (Freq), Guatambu, SC, 2010.

\begin{tabular}{|c|c|c|c|c|c|c|c|}
\hline Classe & Área livre & $\mathbf{N}$ & Freq. \% & Classe & Distância & $\mathbf{N}$ & Freq.\% \\
\hline 1 & $<1$ & 32 & 40 & 1 & $<3,0$ & 30 & 37,5 \\
\hline \multirow[t]{7}{*}{2} & $>1$ & 48 & 60 & 2 & $3,1-6$ & 27 & 33,75 \\
\hline & & & 0 & 3 & $6,1-9$ & 16 & 20 \\
\hline & & & & 4 & $9,1-12$ & 4 & 5 \\
\hline & & & & 5 & $12,1-15$ & 1 & 1,25 \\
\hline & & & & 6 & $15,1-18$ & 1 & 1,25 \\
\hline & & & & 7 & $>18,1$ & 1 & 1,25 \\
\hline & & 80 & 100 & & & 80 & 100 \\
\hline
\end{tabular}

A situação de sanidade das árvores apresentou-se de forma satisfatória, já que $73,75 \%$ dos indivíduos mostraram-se saudáveis (figura 4), e a ocorrência de podas também mostra um quadro favorável em relação ao bom desenvolvimento das árvores implantadas (tabela 5).

Tabela 5 - Sanidade e ocorrência de podas das árvores encontradas no município de Guatambu, com respectivas abundâncias (N) e freqüências (Freq), Guatambu, SC, 2010.

\begin{tabular}{cccccccc}
\hline Classe & Sanidade & N & Freq \% & Classe & Poda & N & Freq \% \\
\hline 1 & SA & 59 & 73,75 & 1 & Sim & 70 & 87,5 \\
2 & IM & 12 & 15 & 2 & Não & 10 & 12,5 \\
3 & $\mathrm{P}$ & 7 & 8,75 & & & & \\
4 & $\mathrm{IM}+\mathrm{P}$ & 2 & 2,5 & & & & 80 \\
\hline Total & & 80 & 100 & & & 100 \\
\hline
\end{tabular}

Onde: $\mathrm{SA}=$ saudável ; IM = Injúria mecânica; $\mathrm{P}=$ Pragas; $\mathrm{IM}+\mathrm{P}=$ Injúria mecânica + pragas; S= Sim; $\mathrm{N}=\mathrm{Não}$ 


\section{Monografias Ambientais}

REMOA (Revista Eletrônica do Curso de Especialização em Educação Ambiental da UFSM)

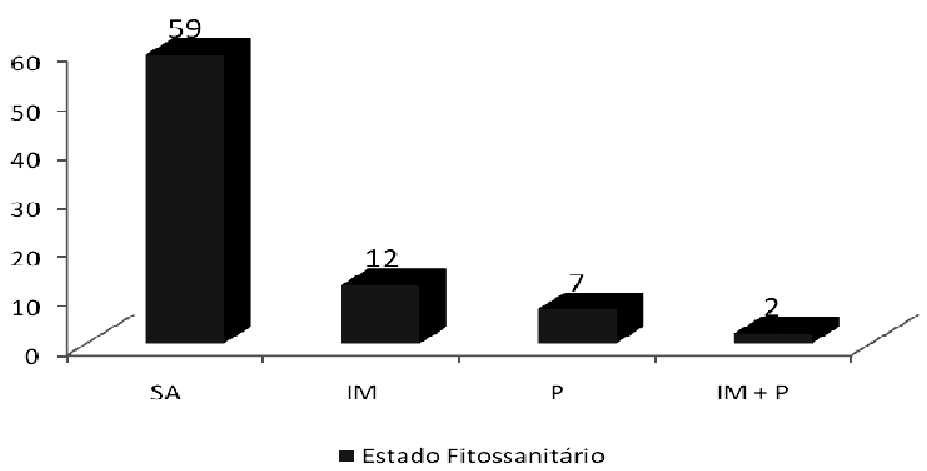

Figura 4 - Número de indivíduos por estado fitossanitário, Guatambu, SC, 2010. (SA= saudável ; IM = Injúria mecânica; $P=$ Pragas; IM + P = Injúria mecânica + pragas.)

\section{CONCLUSÕES E RECOMENDAÇÕES}

As espécies mais abundantes foram Ligustrum lucidum e Balforodendrum riedelianum. Os maiores conflitos observados foram a pequena dimensão de área livre e algumas árvores eram muito jovens para o plantio. Quanto à altura, as espécies apresentaram uma freqüência de $37 \%$ de árvores de pequeno porte, ou seja, não apresentando conflito com fiação e elementos arquitetônicos.

E mais, verifica-se a utilização de espécies exóticas em restrição de nativas, que quando utilizadas agregam valor de diversidade a paisagem. A espécie Cinnamomum zeylanicum possui pequeno porte e é adequada para uso em calçadas, desde que, observada a área livre suficiente (> $1 \mathrm{~m}^{2}$ ). Recentemente, a espécie Ficus Benjamina foi introduzida na arborização do local, apesar de apresentar alguns inconvenientes. Segundo Lorenzi et. al., (2003), deve-se evitar o seu plantio em calçadas e ruas devido ao seu vigor radicular. As demais espécies são de porte médio a grande, não sendo indicadas para calçadas laterais e sim para canteiros centrais ou praças e parques, pois demandam amplo espaço físico. Podem ser utilizadas em áreas não pavimentadas, de preferência áreas abertas ou parques, e em alguns casos, canteiros centrais (quando a dimensão permitir). Há restrições de uso para algumas espécies em estacionamento: T. tipu, visto que a mesma possui uma resina que pode vir a cair nos pára-brisas de carros.

A freqüência de espécies exóticas mostrou-se alta, portanto, sugere-se a introdução de espécies nativas .

Quanto a sanidade, verifica-se uma grande percentagem de indivíduos sadios e poda bem conduzida. Os demais conflitos não se mostraram significativos. Embora nas ruas Ângelo Corá e João Moreira Filho tenham sido encontrados todos esses problemas, a Avenida João Batista não apresentou nenhum conflito, apresentando boa dimensão de área livre, bem como espécies adequadas e de boa sanidade, como pode ser visto no anexo 1. 
REMOA (Revista Eletrônica do Curso de Especialização em Educação Ambiental da UFSM)

\section{REFERÊNCIAS BIBLIOGRÁFICAS}

ALBUQUERQUE, H.N.; SANTOS, L. Análise da arborização dos bairros do Mirante e Vila Cabral na cidade de Campina Grande - PB. Revista de Biologia e Ciências da Terra, Campina Grande, v.3, n.2. 2003.

AMIR, S. \& MISGAV, A. A Framework for Street Tree Planing in Urban areas in Israel. Anais. Landscape and urban Planning Journal. Ed. Elsevier, 1990.

Arborização urbana. Anais. Secretaria Municipal do Meio Ambiente de Porto Alegre, 1985.

CAVALHEIRO, F. Utilização e alterações ambientais. UNESP/FAPESP, 1991.

CESP. Guia de Arborização. Ed. CESP, 1995; 33p.

COBALCHINI, J. I. Critérios para a escolha de espécies utilizadas na arborização urbana viária. FUPEF, 2004.

CUNHA, G. E.; ZECHMEISTER, D.; MELO, Q. E. Elementos de arquitetura de climatização natural. Ed. UPF, 2005.

DANTAS, I. C. \& de SOUZA, C. M. C. Arborização urbana na cidade de Campina Grande-PB: Inventário e suas espécies. Revista de Biologia e Ciências da Terra. V. 4, n², 2004.

DEMATTÊ, M.E.S.P. Princípios de paisagismo - Série Paisagismo 1. Jaboticabal: Funep, 104p. 1997.

Ed. Aprenda fácil, $2004 ; 243$ p.

ELETROPAULO. Guia de Planejamento e Manejo da Arborização Urbana. Ed. Cesp, 1995.

Empresa brasileira de pesquisa agropecuária - EMBRAPA. Sistema brasileiro de classificação dos solos. Brasília, 1999. $412 p$.

FAMURS. Orientações básicas para manejo da arborização urbana: Planejamento e educação ambiental. FAMURS, 2000; 104p.

FRANCO, C. C. D. M. Programa um Milhão de Árvores - SVMA. Anais. Questão Ambiental Urbana: Cidade de São Paulo. Secretaria Municipal do Verde e do Meio Ambiente, 1993.

FURTAdO, A. E.; MELLO FILHO, L. E. A interação microclima, paisagismo e arquitetura. Boletim Informativo da Sociedade Brasileira de Arborização Urbana. V.7, n.3. 1999.

GONÇALVES, W.; PAIVA, H. N. Árvores para o ambiente urbano

GOOGLE EARTH, Mapa de Guatambu, disponívem em http://maps.google.com.br/maps?hl=pt-BR\&rlz=1T4RNTN_ptBRBR380BR380\&q=guatambu+sc\&um=1\&ie=UTF-8\&hq=\&hnear=Guatamb\%C3\%BA+-

+ SC\&gl=br\&ei=9RY1TJqmIsG88gb33JzJCw\&sa=X\&oi=geocode_result\&ct=title\&resnum=1\&ved=0CBoQ8gEwAA, acessado em julho de 2010 .

Governo do estado de SC: Municípios de SC. Disponível em http://www.sc.gov.br/portalturismo/Default.asp?CodMunicipio=352\&Pag=1, acessado em maio de 2010.

GOYA, C. R. Os jardins e a vegetação do espaço urbano: um patrimônio cultural. Anais. II Congresso Brasileiro de Arborização Urbana. SBAU, 1994.

GRAZIANO, T. T. Viveiros Municipais. Departamento de Horticultura - FCAVJ - UNESP. Notas de Aula, 1994.

LIMA, A. M. L. P. Árvores de Rua. Revista Globo Ciência, no 44, 1995.

LORENZI, H.; SOUZA, H.; TORRES, M. A. V.; BACHER, L. B.; Árvores exóticas no Brasil: madeireiras, ornamentais e aromáticas. Ed. Plantarum, 2003, 368 p. 


\section{Monografias Ambientais}

REMOA (Revista Eletrônica do Curso de Especialização em Educação Ambiental da UFSM)

MACEDO, S.S. Quadro do paisagismo no Brasil. Ed. Quapá, 1999; 142 p.

MARCUCCI, D.J. landscape history as a planning tool. Landscape and Urban Planning Journal, n.49; Ed. Elsevier, 2000. MARTO, G.B.T.; BARRICHELO, L.E.G.; SILVA FILHO, D.F.; MULLER, P.H. Arborização Urbana. 2006. Disponível em: http://www.infobibos.com/Artigos/ArborizacaoUrbana/ArborizacaoUrbana.htm. Acessado em junho de 2008.

MELLO FILHO, L. E. Arborização urbana. Encontro nacional sobre

MENESES, C.H.S.G.; SOUSA, E.B.M.; MEDEIROS, F.P.; MENEZES, I.R.; ALBUQUERQUE, H.N.; SANTOS, L. Análise da arborização dos bairros do Mirante e Vila Cabral na cidade de Campina Grande - PB. Revista de Biologia e Ciências da Terra, v.3, $\mathrm{n}^{\circ} 2,2003$.

MESQUITA, L. B. Arborização do Recife: notas técnicas para ajustes na execução e manutenção. Secretaria do Planejamento Urbano e Ambiental da Prefeitura da cidade do Recife, 1996; 88 p.

MILANO, M. S. Curso de Manejo de Áreas Silvestres. Ed. FUPEF, 1983.

MILANO, M. S. O planejamento da arborização, as necessidades de manejo e tratamentos culturais das árvores de ruas de Curitiba, PR. Revista Floresta, v.17, n²1/2, jun./dez.1987.

PAIVA, H.N. Seleção de espécies para arborização urbana. Revista Ação Ambiental, UFV, v.2, n.9, 2000.

PEDROSA, J.B. Arborização de cidades e rodovias. Ed. E.F. 1983.

PHILLIPS, L. E. Urban tree: guide for selection, maintenance and master planning. Ed. McGraw-Hill, 1993.

PIVETTA, K. F. L.; SILVA FILHO, D. M. Arborização Urbana. Boletim Acadêmico. Série Arborização Urbana. UNESP/FCAV/FUNEP, 2002.

PRASS, C.H. Avaliação da arborização urbana na cidade de Quinze de Novembro - RS. Santa Maria, Universidade Federal de Santa Maria, Departamento de Ciências Florestais, 2004. (Relatório de Estágio Curricular).

ROBBA, F.; MACEDO, S. S. Praças brasileiras. Ed. USP, 2003; 311 p.

Santos, N. R. Z.; Teixeira, I. F. Arborização de vias públicas: ambiente x vegetação .Ed. Pallotti, 2001; 135 p.

SOARES, M. P. Verdes Urbanos e Rurais: Orientação para arborização de cidades e sítios campesinos. Ed. Cinco Continentes, 1998.

TEIXEIRA, I.F. Análise qualitativa da arborização de ruas do Conjunto habitacional Tancredo Neves, Santa Maria, RS. Revista Ciência Florestal, Santa Maria, v.9, n.2, 1999.

YAMAMOTO, M. A.; SCHIMIDT, R. O. L; COUTO, H. T. Z.; SILVA FILHO, D. F. Árvores Urbanas Piracicaba 2004. Disponível em http://Imq.esalq.usp.br/ dfsilva/arvores_urbanas.pdf, acessado em maio de 2010. 
ANEXOS

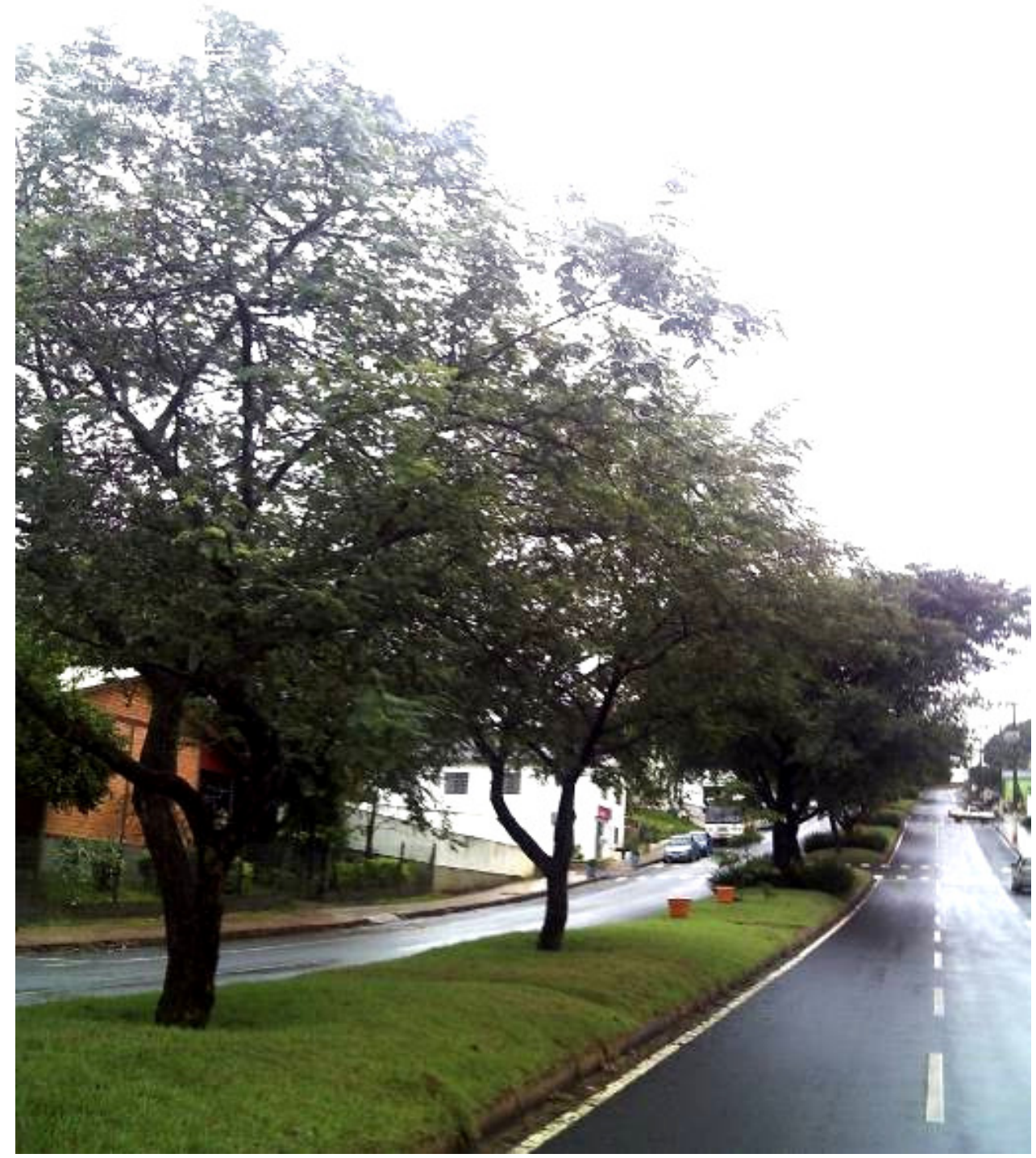

Anexo 1 - Aspecto da arborização da Avenida João Batista 
(())

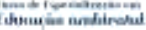

REMOA
BOHNER et al., vol.(3), n³, p.532-546, 2011

\section{Monografias Ambientais}

(Revista Eletrônica do Curso de Especialização em Educação Ambiental da UFSM)

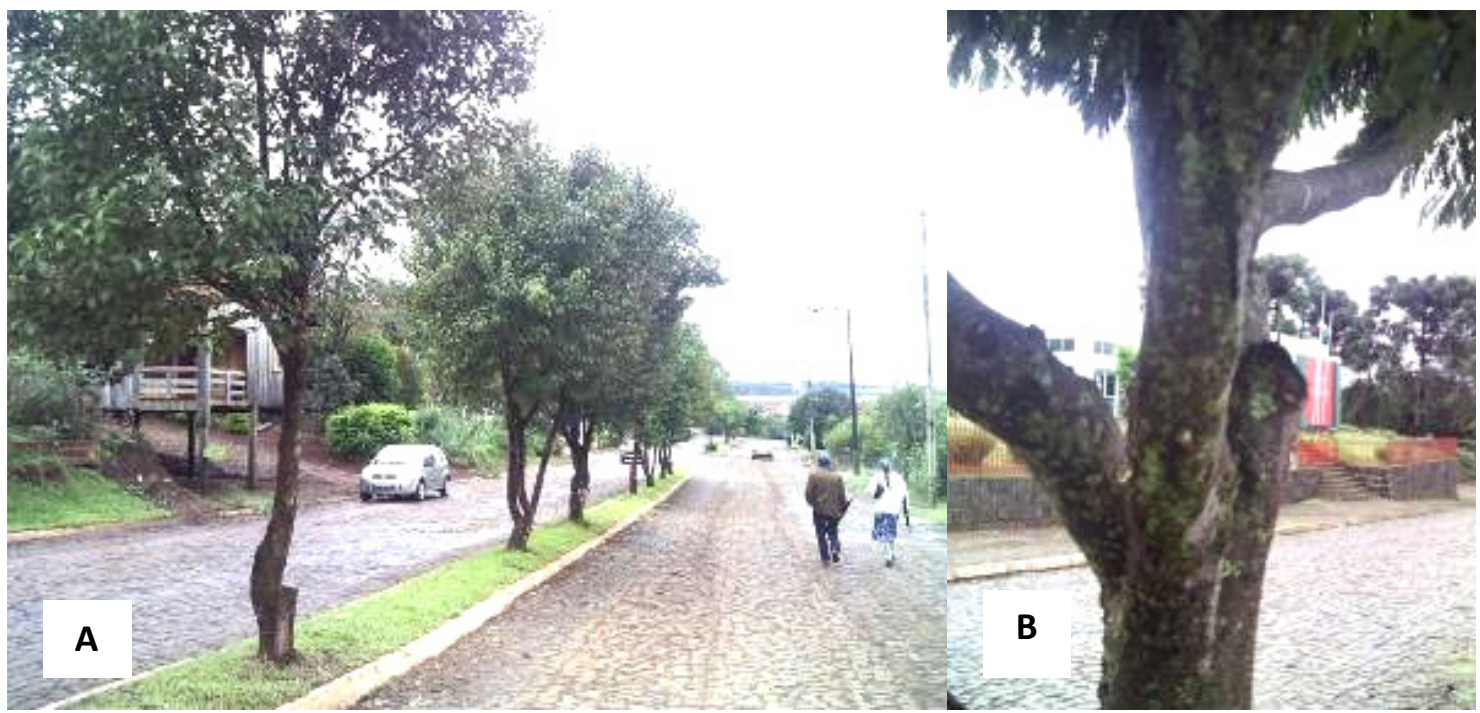

Anexo 2 - a) Poda inadequada e área livre insuficiente e; b) injúria mecânica (Fonte: Bohner, 2010.).

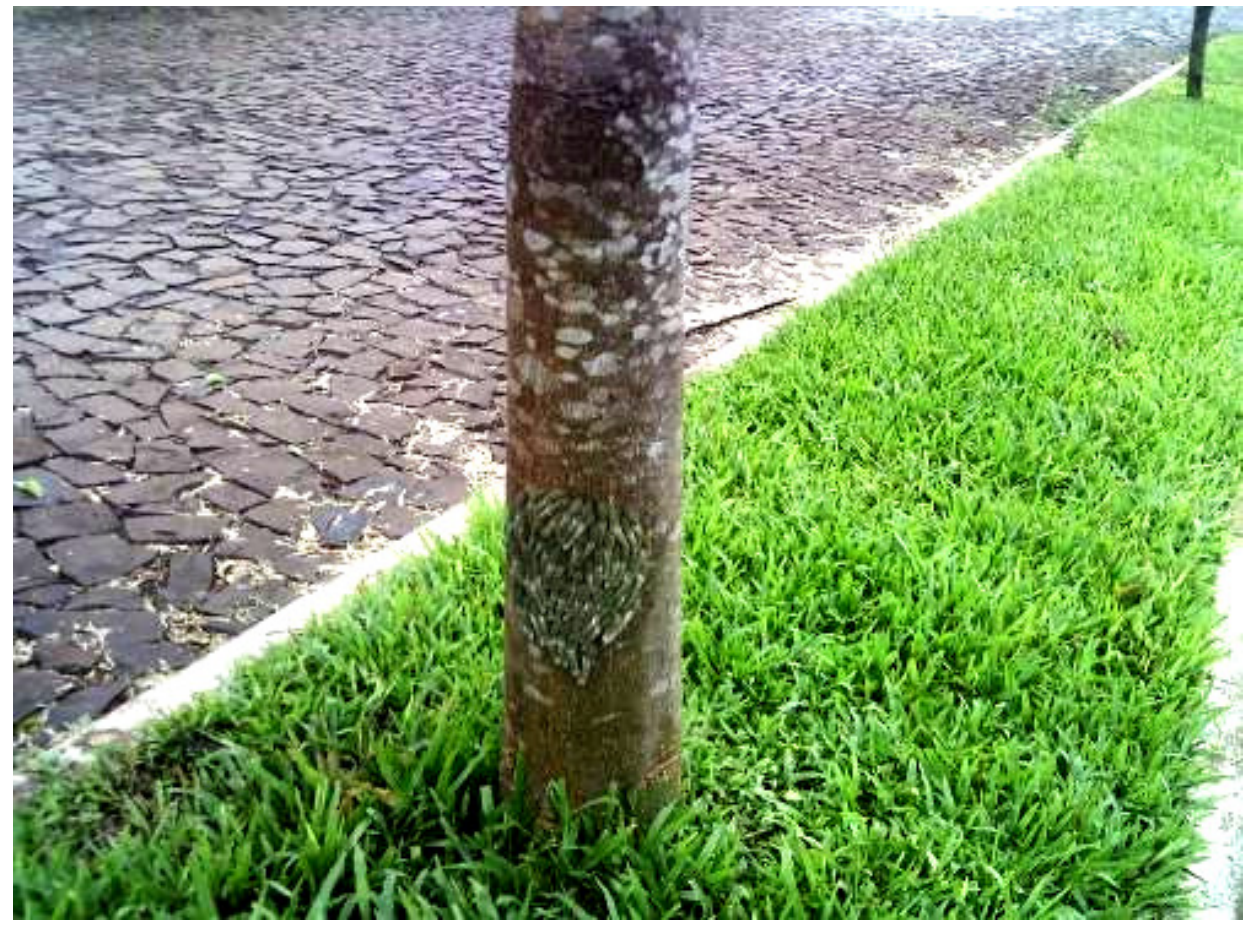

Anexo 3 - Ataque de pragas (Fonte: Bohner, 2010.). 